\title{
DISCIPLINA DE ENSINO RELIGIOSO: ESCASSEZ DE PROFESSORES PARA EDUCAÇÃO DE CAMPO NO MUNICÍPIO DE GUARAPUAVA-PR
}

Elisiane Zvirl

RESUMO: A disciplina de Ensino Religioso envolve estudo da diversidade de religiões existentes, assim como, respeito a diferentes crenças e símbolos religiosos, sendo assim, envolve o respeito ao próximo, respeito à multiculturalidade. Nesse sentido, o objetivo da pesquisa foi compreender a importância da especialização em Ensino Religioso e compreender o perfil de formação dos inscritos para atuarem como professores da disciplina na Educação de Campo no município de Guarapuava-PR. A metodologia do trabalho envolveu leituras bibliográficas e levantamento de dados sobre o número de inscritos e suas pontuações na classificação final para atuarem da Educação Estadual no ano de 2016. OS dados foram coletados no site do Núcleo Regional de Educação de Guarapuava-PR, Dados resultantes da pesquisa nos mostram que ainda é recente a disciplina no Brasil, pois foi aprovada em 1996. Com o levantamento de dados junto ao Núcleo Regional de Guarapuava foi possível concluir que a maioria dos professores que está dando aula hoje de Ensino Religioso na Educação de Campo não possui especialização na área.

Palavras-chaves: Ensino Religioso, Especialização de Ensino Religioso, Guarapuava-PR, Diversidade Religiosa.

\section{RELIGIOUS EDUCATION DISCIPLINE: SCREENING OF TEACHERS FOR FIELD EDUCATION IN THE MUNICIPALITY OF GUARAPUAVA-PR}

\begin{abstract}
The discipline of Religious Education involves studying the diversity of existing religions, as well as respect for different religious beliefs and symbols, and thus involves respect for others, respect for multiculturalism. In this sense, the objective of the research was to understand the importance of specialization in Religious Education and to understand the training profile of the enrolled ones to act as teachers of the discipline in Field Education in the city of Guarapuava-PR. The methodology of the work involved bibliographical readings and data collection on the number of enrollees and their scores in the final classification to act in the State Education in the year 2016. The data were collected on the website of the Regional Core of Education of Guarapuava-PR, resulting data of the research show that the discipline is still recent in Brazil, since it was approved in 1996. With the data collection with the Regional Center of Guarapuava it was possible to conclude that most of the teachers who are teaching classes today in Religious Education in Field Education has no specialization in the area.
\end{abstract}

Key-words: Religious Education, Specialization in Religious Education, Guarapuava-PR, Religious Diversity.

\footnotetext{
${ }^{1}$ Graduada em História e mestranda em História pela mesma instituição Universidade Estadual do Centro Oeste - UNICENTRO. Contato: elisiane07@ hotmail.com
} 


\section{INTRODUÇÃO}

A emenda do art. 33 da Lei das Diretrizes e Bases da educação², Lei nº 9.394 de 20 de Dezembro de 1996, com a publicação dos Parâmetros Curriculares Nacionais $\left(\mathrm{PCN}^{3}\right)$ do Ensino Religioso reconhece a disciplina não como Ensino de Religião e sim como Ensino das Religiões. É importante lembrar que desde o período colonial até o final do século XX a igreja católica dominava o ensino religioso e empregava o ensino do cristianismo, sendo assim, com o art.33 das LDB a disciplina torna possível guiar os alunos a conhecer e respeitar a diversidade religiosa existente a nível mundial.

Na Educação Pública a disciplina é empregada atualmente nas séries iniciais do Ensino Fundamental I e II, ou seja, a criança tem acesso a disciplina dos 6 aos 14 anos, idade em que tem maior curiosidade sobre as coisas, idade de conhecer o novo, e o mais importante, idade onde se torna mais fácil construir com o educando a compreensão e respeito ao diferente. Sendo assim, a disciplina tem uma enorme importância na formação do cidadão, visto que nos encontramos em uma sociedade repleta de crenças, tanto no nosso convívio quanto as que presenciamos na mídia, como por exemplo, podemos citar jornais, novelas, internet, entre outros.

Nesse sentido, busca-se nesse trabalho compreender a importância da disciplina de Ensino Religioso para formação cidadã dos alunos no ensino fundamental; Buscasse também entender o que a lei define como Ensino Religioso hoje e quais requisitos para formação desse professor na rede Estadual de Ensino através do edital de seleção professores de Ensino Religioso na Educação de Campo ${ }^{4}$ no município de Guarapuava-PR ${ }^{5}$.

\footnotetext{
2 A "LDB - Lei de Diretrizes e Bases da Educação, no 9.394/96 - ela é uma legislação com a função de organizar a estrutura da educação brasileira, la influencia diretamente na formação escolar e acadêmica". Disponível em < http://soparaprofessoras.blogspot.com.br/2011/05/importancia-dos-pcns-e-da-ldb.html>. Último acesso em: $15 / 08 / 2016$

${ }^{3}$ Os PCNs "constituem-se em referências nacionais para o Ensino Básico, a primeira etapa para a concretização curricular do Brasil, definindo as metas para a educação estabelecidas pelas políticas públicas do Ministério da Educação". Os PCNs são de extrema importância e "podem ser usados como recursos para a construção, elaboração, reelaboração ou adaptações curriculares pelas Secretarias de Educação”. É importante ressaltar que cada Núcleo Regional de Educação pode adaptar os PCNs conforme sua realidade social local.

Disponível em <Fonte: http://soparaprofessoras.blogspot.com.br/2011/05/importancia-dos-pcns-e-da-ldb.html . Último acesso em: 15/08/2016

${ }^{4}$ É importante entender o que é Educação de Campo para compreender a complexidade de números de professionais nessas áreas. Educação de Campo se define por Colégios ou outros tipos de espaços educativos retirados da cidade, geralmente se localizam em meio agropecuário, como também os "espaços pesqueiros, a populações ribeirinhas, caiçaras e extrativistas." (...) "É destinada às populações rurais nas diversas produções de vida já citadas, assim como serve também como denominação a educação para comunidades quilombolas, em assentamento ou indígena.".

Fonte: http://educacaointegral.org.br/glossario/educacao-no-campo/>. Último acesso em: 15/08/2016

5 “Guarapuava é um município brasileiro do estado do Paraná, do qual é o segundo em extensão e o nono mais populoso, com 179256 habitantes". (...) "segundo estimativas do IBGE de 2016. Considerado um polo regional
} 
Fez parte da metodologia leituras bibliográficas para compreender a importância da disciplina de Ensino Religioso na formação do cidadão. Outro aspecto metodológico utilizado na pesquisa foi à análise da quantidade de inscritos para professor de Ensino Religioso em Educação de Campo no município de Guarapuava-PR e quantos foram chamados até março de 2016.

Essa análise foi feita com o objetivo de intuito de compreender a especificidade e complexidade da disciplina e também compreender se sobraram ou faltaram profissionais $\mathrm{s}$ especializados em Ensino Religioso na Educação de Campo no município de Guarapuava PR.

\title{
A IMPORTÂNCIA DA DISCIPLINA DE ENSINO RELIGIOSO
}

De acordo com o autor Queiroz (2013), o Ensino Religioso é essencial para formação da criança, é parte fundamentos dos diferentes alicerces do conhecimento que são construídos, pois com essa disciplina é possível guiar o aluno a conhecer diferentes grupos e diferentes segmentos e costumes religiosos. O professor pode preparar suas aulas de modo que leve os alunos a problematizarem o "objeto de estudo" (QUEIROZ, 2013). A construção do conhecimento envolve ainda a valorização de suas próprias opiniões formadas, essa afirmação fica mais clara de acordo com o autor na seguinte citação:

\begin{abstract}
Nos anos iniciais do Ensino Fundamental, é importante que se dê um enfoque à formação das primeiras noções sobre identidade, alteridade e transcendência; que se trabalhe a elaboração dos saberes e conhecimentos básicos dos educandos sobre si mesmo, sobre o outro e sobre a importância de se viver em comunidade; que se facilite a constituição de comportamentos básicos que promovam o cuidado, o amor e o respeito uns com os outros e com a natureza. Levá-los a compreender a importância de cada um na formação da comunidade, valorizando as atitudes, as opiniões, as críticas de si mesmo e de seus colegas, enfatizando a autoestima e a afirmação uns dos outros; manifestar atitudes de respeito, de cuidado e de responsabilidade por si mesmo, pelo outro e pela natureza; reconhecer a importância do outro e da natureza para a continuidade da vida; perceber que a prática do diálogo exige disposição de ouvir e respeitar as ideias do outro; exercitar a prática do diálogo inter-religioso e intercultural; identificar as diferentes formas de manifestação do transcendente; e, por fim, conhecer a importância dos símbolos para as tradições religiosas e apontar valores necessários para o convívio em comunidade são objetivos prementes da disciplina em apreço. (QUEIROZ, 2013, p.32).
\end{abstract}

de desenvolvimento com forte influência sobre os municípios vizinhos, faz parte também de um entroncamento rodoferroviário de importância nacional denominado corredor do $\underline{\text { MERCOSUL, entre os municípios de Foz do }}$ Iguaçu e Curitiba"

Disponível em <Fonte: https://pt.wikipedia.org/wiki/Guarapuava>. Último acesso em: 15/08/2016 
A citação acima nos permite entender que a disciplina de Ensino Religioso enriquece o aluno para o convívio em sociedade, pois na disciplina é trabalhado valores que compreendem a existência de diversos "símbolos religiosos", ou seja, essa disciplina facilita para conduzir o estudante a compreender que não é somente sua religião que é certa, que não existem certas ou erradas e sim, que todas tem suas crenças, seus símbolos e seu modo de ser e viver e temos que respeita-las, temos que deixar de lado o olhar de estranhamento e entender também que outros grupos religiosos também tem alguma opinião formada sobre nossas crenças.

Nesse sentido, a disciplina vai além de estudos sobre a diversidade religiosa existente, ela trabalha ainda a questão do preconceito. É normal que com o decorrer das aulas o aluno identifique praticas religiosas e símbolos religiosos de seus familiares em suas casas e é claro, vai agir com respeito. O autor Queiroz (2013) ressalta que a disciplina tem a possibilidade de mostrar ao aluno que dentre as diferentes praticas religiosas existentes temos que ter respeito e preservar amizades, pois é essa serenidade que devemos ter em sociedade, "o saber respeitar o outro" (QUEIROZ, 2013)

Para melhor compreendermos a disciplina de Ensino Religioso é importante considerar que o professor em sala de aula não deve propagar uma religião em si e sim mostrar a existência de diferentes religiões. Dentre os conteúdos que compõe a disciplina podemos citar:

estudo da alteridade, das culturas e tradições religiosas, do espaço sagrado, dos símbolos, dos rituais, das mitologias, da vida e da morte, do tempo sacralizado e celebrado, das personagens importantes que fizeram história, do sagrado feminino, da arte religiosa, entre outros. (QUEIROZ, 2013, p.36).

Nesse sentido a construção do conhecimento é enriquecida, visto que o aluno está em fase da construção da identidade e nada melhor do que construir a identidade em meio ao conhecimento da diversidade, pois quando o aluno sai com esse olhar da escola é como se ele colocasse uma lente, ou seja, olhará com outros olhos o diferente, olhará com uma visão mais ampla entendo a complexidade a abstração, mas principalmente respeitando o diferente.

\section{DEFINIÇÃO DE ENSINO RELIGIOSO DE ACORDO COM A LEI No 9.394 DE 20 DE DEZEMBRO DE 1996}

De acordo com o Markus (2002), o final do século XX é marcado por diversas rupturas e questionamentos, o autor ressalta que é o período em que: 
acontece o processo de abertura política no país; difunde-se a liberdade de imprensa; estão em voga os debates sobre a teologia da libertação; o fenômeno da diversidade religiosa se torna evidente e visível; movimentos sociais e culturais se afirmam e reivindicam ações diferenciadas; surge uma nova concepção de evangelização; e uma nova Constituição reconhece e assegura o respeito pelas diversidades culturais e religiosas. (MARKUS, 2002, p.35-36).

Nesse sentido a escola rompe com certos paradigmas e da uma virada em torno da discussão da diversidade, isso fica muito claro quando comparamos a diferença entre o artigo de 1996 com o anterior. O primeiro artigo, sendo o 210 da $1^{\circ}$ constituição consta o seguinte texto: “O Ensino Religioso, de matrícula facultativa, constituirá disciplina dos horários normais das escolas públicas de ensino fundamental” (MARKUS, 2002, apud BRASIL, Constituição da República Federativa do Brasil, p. 85).

Vejamos então o outro artigo, sendo ele de 20 de dezembro de 1996 que "sanciona a lei $n^{\circ}$ 9.394/12/96 que recebe uma redação dia 22 de julho de 1997, sob a lei $n^{\circ}$ 9.475" (MARKUS,2002) enfatiza que:

\footnotetext{
"O ensino religioso, de matrícula facultativa, é parte integrante da formação básica do cidadão e constitui disciplina dos horários normais das escolas públicas de ensino fundamental, assegurado o respeito à diversidade cultural religiosa do Brasil, vedadas quaisquer formas de proselitismo.

$1^{\circ}$ - Os sistemas de ensino regulamentarão os procedimentos para a definição dos conteúdos do ensino religioso e estabelecerão as normas para a habilitação e admissão dos professores.

$2^{\circ}$ - Os sistemas de ensino ouvirão entidade civil, constituída pelas diferentes denominações religiosas, para a definição dos conteúdos do ensino religioso" (MARKUS, 2002, apud Lurdes CARON (org.) e Equipe do GRERE, O Ensino Religioso na nova LDB, p. 27.)
}

A principal diferença entre os artigos é em relação ao aspecto culturas e de inclusão de diversidades, pois enquanto na primeira constavam apenas aspectos sobre uma disciplina qualquer o novo artigo inclui que é uma disciplina indispensável para formação do cidadão e principalmente agora a disciplina deve ser constituída levando em consideração as "diferentes dominações religiosas". Nesse sentido a construção do currículo deve abarcar não somente uma religião e sim diversas religiões para permitir com que o aluno compreenda a diversidade de grupos e símbolos religiosos existentes e principalmente saber respeitar essa diferença. (SILVA, 2015)

É uma perda muito grande de construção do conhecimento quando um professor de ensino religioso acaba privilegiando uma religião e acaba levando, por exemplo, textos bíblicos ou cantos de louvor para sala de aula como se fosse uma aula catequética, pois se o professor leva para sala de aula 
material de uma religião deve levar de várias e trabalhar com uma metodologia que torne possível o aluno compreender a existência da diversidade religiosa.

O professor pode inclusive trabalhar a partir da realidade dos seus alunos, pois uma turma possui estudantes com duas ou mais religiões, o professor pode conduzi-los a refletirem sobre essa realidade e principalmente não discriminar o diferente e sim assumir um compromisso de respeito. (MARKUS,2002)

\section{FORMAÇÃO DO PROFESSOR DE ENSINO RELIGIOSO}

Muito falamos até agora sobre a importância da disciplina de Ensino Religioso no ensino fundamental para construção do conhecimento e do senso crítico do aluno e principalmente do respeito à diversidade, mas ainda não problematizamos qual a formação necessária para um professor de Ensino Religioso hoje, então vamos refletir um pouco sobre essa questão.

De acordo com a Lei n. 9.475/97 na resolução n. 02/98 no artigo 62:

\footnotetext{
"a formação de docentes para atuar na educação básica far-se-á em nível superior, em curso de licenciatura, de graduação plena, em universidades e institutos superiores de educação, admitida, como formação mínima para o exercício do magistério na educação infantil e nas quatro primeiras séries do ensino fundamental, a oferecida em nível médio, na modalidade Normal.” (QUEIROZ,)
}

Nesse sentido, a formação especializada é ainda um assunto muito debatido, pois para um ensino de qualidade não basta o professor ter apenas uma graduação e sim especializações, cursos de capacitação ou até mesmo uma Pós-Graduação Strito Sensu, nesse sentido o artigo 214 “Considera o Ensino Religioso uma das áreas de formação, visto que será a religiosidade uma das dimensões do ser humano integral que a escola pretende alcançar" (MARKUS, 2002).

Visando a qualidade de ensino pensamos que o Estado deve oferecer cursos que tornem possível o professor ou licenciando se especializar em determinada área, esse é o requisito menino para um ensino de qualidade, mas nem sempre isso acontece.

Em relação a um conhecimento mais profundo sobre Ensino Religioso ainda é um "assunto delicado no Brasil", pois se olharmos editais de concursos para professores ou os próprios Processo Seletivo (PSS) notamos que tendo uma licenciatura na área de Ciências Humanas já torna possível ser professor de Ensino Religioso, isso porque com certeza há escassez de professores especializados na área. 
Sendo assim, os professores sessa disciplina que estão nas escolas hoje são formados em uma dessas disciplinas: História, Filosofia, Sociologia ou Psicologia; Lembrando que essas disciplinas fornecem apenas "a base para respeito as manifestações religiosas" (MARKUS,2002, p.44), pois é num conhecimento mais aprofundado na área que torna possível o professor ter:

\footnotetext{
"uma visão história de como se procederam as relações entre diversas religiões e culturas. Ambos devem tomar conhecimento e entender os processos que explicam porque algumas religiões e denominações estão mais ou menos representadas no ensino atual, por que outras foram excluídas e consideradas diabólicas ou inferiores" (MARKUS, 2002, p.44"
}

Desse modo, o perfil do professor de Ensino Religioso envolve a capacidade de saber trabalhar com a multiculturalidade e a própria diversidade existente na escola, esse profissional deve saber conduzir os alunos a refletirem sobre a diversidade existente e principalmente, saber respeitar as diferentes crenças, ou seja, saber lidar com uma visão conjuntural e utilizar isso no processo de construção do conhecimento.

\section{PROFESSORES DE ENSINO RELIGIOSO NA EDUCAÇÃO DE CAMPO NO MUNICÍPIO DE GUARAPUAVA-PR}

De acordo com o edital 59/2015 do Núcleo Regional de Educação do Município de Guarapuava, os requisitos necessários para inscrições 2016 para a função de professor de Ensino Religioso para Rede Estadual de Ensino são os seguintes:

(Quadro I)

\begin{tabular}{|l|l|l|}
\hline ETAPA & DESCRIÇÃO DA ETAPA & REQUISITOS PARA INSCRIÇÃO \\
\hline
\end{tabular}

6 Esse edital está disponível no seguinte link Disponível em <http://www.educacao.pr.gov.br/arquivos/File/pss/pss2015/edital592015gsseed_prof_retificado.pdf>. Último acesso em: 15/08/2016 


\begin{tabular}{|c|c|c|}
\hline $\begin{array}{l}\text { ETAPA } \\
2\end{array}$ & $\begin{array}{l}\text { Ensino Religioso Professor de } \\
\text { Ensino Religioso na Educação } \\
\text { Básica, e modalidades Educação do } \\
\text { Campo, Educação Escolar Indígena e } \\
\text { Educação Escolar Quilombola. }\end{array}$ & $\begin{array}{l}\text { Formação em cursos de licenciatura na } \\
\text { área das Ciências Humanas: Filosofia, } \\
\text { História, Ciências Sociais e Pedagogia, } \\
\text { preferencialmente com Especialização em } \\
\text { Ensino Religioso, conforme Deliberação } \\
\text { n. }{ }^{\circ} 01 / 06 \text { CEE/PR }\end{array}$ \\
\hline
\end{tabular}

No quadro acima consta dados retirados do edital 59/2015 e fica claro o que já citamos acima a respeito da formação do professor de Ensino Religioso, pois o edital especifica que o requisito principal é a formação em uma licenciatura dentro das áreas de ciências humanas (História, Ciências Sociais e Pedagogia), no edital ainda consta que é dado preferência para quem tem especialização em Ensino Religioso. Nesse sentido vai por “água abaixo” o que já foi descrito acima sobre a importância de uma especialização para o professor ter um estudo mais aprofundado sobre Ensino Religioso, pois se existir um grande número de vagas e poucos inscritos com especialização ocorrerá um grande número de professores sem um estudo mais profundo na disciplina.

Agora vamos verificar a imagem abaixo (Quadro2), essa é uma imagem do edital 59/2015, referente ao valor da pontuação de títulos para a classificação de professores de Ensino Religioso no município de Guarapuava. 
(Quadro 2)

\begin{tabular}{|c|c|c|}
\hline \multicolumn{3}{|l|}{ ETAPA 2 - ENSINO RELIGIOSO - Código 201527} \\
\hline \multicolumn{3}{|c|}{$\begin{array}{l}\text { Professor de Ensino Religioso na Educação Básica: todos os municípios do Estado do Paraná } \\
\text { Professor de Ensino Religioso na modalidade de Educaçăo do Campo: Anexo VII - quadro } 3 \\
\text { Professor de Ensino Religioso na modalidade de Educaçăo Escolar Indígena: Anexo VII - quadro } 4 \\
\text { Professor de Ensino Religioso na modalidade de Educaçăo Escolar Quilombola - Adrianópolis e Palmas }\end{array}$} \\
\hline $\begin{array}{l}\text { ESCOLARIDADE OBRIGATÓRIA } \\
\text { De acordo com Deliberaçấo 01/06 - CEE/PR } \\
\text { Será excluido do processo seletivo o candidato que nâo comprovar a escolaridade informada. }\end{array}$ & PONTOS & $\begin{array}{l}\text { PONTUAÇÃO } \\
\text { MÁXIMA }\end{array}$ \\
\hline \multicolumn{2}{|l|}{ Nivel superior completo - (LP) } & \multirow{8}{*}{75} \\
\hline $\begin{array}{l}\text { a) Certificado de Pós-Graduaçăo em Ensino Religioso, acompanhado de diploma de } \\
\text { curso superior de Licenciatura Plena em Filosofia, ou em: História; Ciências Sociais; } \\
\text { Sociologia; Pedagogia ou Geografia; }\end{array}$ & 75 & \\
\hline $\begin{array}{l}\text { b) Diploma de Licenciatura Plena em Filosofia, ou em: História; Ciencias Sociais; } \\
\text { Sociologia; Pedagogia ou Geografia; }\end{array}$ & 60 & \\
\hline $\begin{array}{l}\text { c) Certificado de Pós-Graduação em Ensino Religioso, acompanhado de diploma de } \\
\text { curso superior de Licenciatura Plena em qualquer disciplina da Educaçăo Básica; }\end{array}$ & 55 & \\
\hline $\begin{array}{l}\text { d) Certificado de Pós-Graduação em Ensino Religioso, acompanhado de diploma de } \\
\text { Bacharelado em Filosofia, ou em: História; Ciências Sociais; Sociologia; Pedagogia ou } \\
\text { Geografia; }\end{array}$ & 35 & \\
\hline $\begin{array}{l}\text { e) Diploma de Bacharelado em Filosofia, ou em: História; Ciências Sociais; Sociologia } \\
\text { ou Geografia. }\end{array}$ & 25 & \\
\hline \multicolumn{2}{|l|}{ Licenciatura Curta- (LC) } & \\
\hline $\begin{array}{l}\text { f) Certificado de Pós-Graduaçăo em Ensino Religioso, acompanhado de diploma de } \\
\text { Licenciatura Curta em História, Geografia ou Estudos Sociais. }\end{array}$ & 45 & \\
\hline \multicolumn{3}{|l|}{ TEMPO DE SERVIÇO (Periodo de 01/07/2005 a 30/06/2015) } \\
\hline $\begin{array}{l}\text { a) Tempo de serviço na função ou cargo de Professor, ou Professor Pedagogo, ou TILS, } \\
\text { como contratado pela SEED, na Educação Básica e suas modalidades. Năo necessita } \\
\text { comprovaçăo. Registro automático no Sistema PSS. }\end{array}$ & 1 por ano & \multirow{4}{*}{10} \\
\hline 1) Tempo de serviço exonerado prestado como efetivo da SEED - QPM/QUP. & 1 por ano & \\
\hline $\begin{array}{l}\text { 2) Durante o período de inscriçőes, o candidato deve excluir periodo de tempo de } \\
\text { serviço já utilizado ou em processo de utilizaçăo para aposentadoria, via Sistema PSS, } \\
\text { na opçăo que consta para este fim. }\end{array}$ & 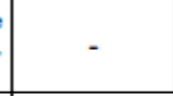 & \\
\hline $\begin{array}{l}\text { b) Tempo de serviço na funçăo ou cargo de Professor, ou Professor Pedagogo, ou TILS, } \\
\text { em estabelecimentos de ensino da rede particular e/ou de outras secretarias da rede } \\
\text { pública estadual, municipal, federal e de outros estados. }\end{array}$ & 1 por ano & \\
\hline \multicolumn{3}{|l|}{ APERFEIÇOAMENTO PROFISSIONAL } \\
\hline $\begin{array}{l}\text { a) Certificado de Pós-Graduação lato sensu, em nivel de Especializaçăo, ou stricto } \\
\text { sensu, em nivel de Mestrado, Doutorado ou Pós-Doutorado. }\end{array}$ & 5 por curso & \multirow{2}{*}{15} \\
\hline $\begin{array}{l}\text { b) Diploma de outro curso superior completo, diferente do utilizado como requisito de } \\
\text { escolaridade. }\end{array}$ & 5 por curso & \\
\hline \multicolumn{2}{|l|}{ PONTUAÇĀO MÁXIMA } & 100 \\
\hline
\end{tabular}

Disponível

http://www.educacao.pr.gov.br/arquivos/File/pss/pss2015/edital592015gsseed_prof_retificado.pdf $>$ Último acesso em: 15/08/2016

No quadro acima notamos que os inscritos com graduação e especialização em Ensino Religioso terão 75 pontos e os inscritos somente com Licenciatura obterão 60 pontos. Nesse processo seletivo para o município de Guarapuava em Educação de Campo teve somente 12 inscritos (notasse isso no quadro abaixo) e sobre esses inscritos foi mapeada a pontuação de todos, vamos analisar essa pontuação no quadro 4: 
$(\text { Quadro 3) })^{7}$

\begin{tabular}{|l|l|l|}
\hline \multicolumn{2}{|c|}{ CLASSIFICAÇÃO FINAL -EDITAL 59/2015 } \\
\hline \multicolumn{2}{|c|}{ ETAPA 2 } \\
\hline Modalidade: Educação de Campo & $\mathrm{N}^{\circ}$ de inscritos & 12 \\
\hline
\end{tabular}

$(\text { Quadro 4) })^{8}$

\begin{tabular}{|l|l|}
\hline \multicolumn{2}{|l|}{ Pontuação dos classificados } \\
\hline $1^{\circ}$ & 78 \\
$2^{\circ}$ & 75 \\
$3^{\circ}$ & 71 \\
4 & 70 \\
$5^{\circ}$ & 68 \\
$6^{\circ}$ & 65 \\
$7^{\circ}$ & 61 \\
$8^{\circ}$ & 61 \\
9 & 60 \\
$10^{\circ}$ & 60 \\
$11^{\circ}$ & 60 \\
$12^{\circ}$ & 60 \\
\hline
\end{tabular}

O quadro quatro é referente à classificação final do processo seletivo no município de Guarapuava para a Etapa de Ensino Religioso-Educação de Campo. Com a pontuação dos classificados notamos que somente dois possuem 75 pontos ou mais, ou seja, de doze somente dois possuem diploma de licenciatura e diploma de especialização em Ensino Religioso.

Agora para finalizar essa reflexão acerca do perfil dos professores de Ensino religioso no município descrito, iremos analisar quantos foram convocados pelo Núcleo Regional de Educação para exercer a função. O quadro seguinte mostra dados sobre as datas das convocações e quantos classificados foram chamados para exercer a função.

\footnotetext{
7 Disponível em: file://C:/Users/elisi/Downloads/Distribui\%C3\%A7\%C3\%A3o\%20de\%20aulas\%20-\%202701-2016\%20(3).pdf >. Último acesso em: 15/08/2016

8 A referência do quadro 4 é a mesma do quadro 3. Disponível em: file://C:/Users/elisi/Downloads/Distribui\%C3\%A7\%C3\%A3o\%20de\%20aulas\%20-\%2027-01-

2016\%20(3).pdf $>$. Último acesso em: 15/08/2016
} 


\begin{tabular}{|c|c|}
\hline \multicolumn{2}{|c|}{ ENSINO RELIGIOSO (Etapa: 02) (Código: 201527) } \\
\hline $\begin{array}{l}27 \text { de janeiro } \\
17 \text { de Fevereiro } \\
26 \text { de Fevereiro }\end{array}$ & $\begin{array}{l}1^{\circ} \text { ao } 3^{\circ}- \\
4^{\circ} \text { e } 5^{\circ}- \\
6^{\circ} \text { ao } 12^{\circ}\end{array}$ \\
\hline 04 de Março de 2016 & $\begin{array}{l}\text { Reconvocação de todos os } \\
\text { Classificados PSS/2016 (em } \\
\text { final de lista) }- \text { Edital } \mathrm{N}^{\circ} \\
59 / 2015 ;\end{array}$ \\
\hline
\end{tabular}

Com esses dados das convocações do quando 5, fica evidente que na primeira chamada já foram convocados os dois que possuíam licenciatura e especialização e nas próximas chamadas já foram convocados os que possuíam somente licenciatura. Notamos ainda que todos foram chamados no primeiro mês do ano letivo (mês de Fevereiro), ou seja, se todos foram convocados temos hoje professores somente com licenciatura em ciências humanas dando aula de Ensino Religioso.

\section{METODOLOGIA}

A metodologia aplicada nessa pesquisa foi a partir de leituras bibliográficas para compreender a importância da disciplina de Ensino Religioso na formação do cidadão. Também fez parte da metodologia a análise da quantidade de inscritos para professor de Ensino Religioso em Educação de Campo no município de Guarapuava-PR e quantos foram chamados até março de 2016.

Essa análise foi feita com o intuito de compreender a especificidade e complexidade da disciplina e também a demanda de profissionais especializados em Ensino Religioso na Educação de Campo. Para isso foram feitas análises documentais, foram usadas listas de inscritos e listas de chamadas no processo seletivo para atuar nas escolas Estaduais de

\footnotetext{
${ }^{9}$ As listas de convocações do processo seletivo do edital $59 ? 2015$ estão disponíveis nos seguintes links: Disponível <file:///C:/Users/elisi/Downloads/Distribui\%C3\%A7\%C3\%A3o\%20de\%20aulas\%20e\%20fun\%C3\%A7\%C3\% B5es\%20-\%2017\%20e\%2018-02-2016\%20(5).pdf>. Último acesso em: 15/08/2016 Disponível em <file:///C:/Users/elisi/Downloads/Distribui\%C3\%A7\%C3\%A3o\%20de\%20aulas\%20-\%2026-022016\%20(1).pdf >. Último acesso em: 15/08/2016 Disponível em <file:///C:/Users/elisi/Downloads/Distribui\%C3\%A7\%C3\%A3o\%20de\%20aulas\%20-\%2004-032016\%20(3).pdf $>$. Último acesso em: 15/08/2016
} 
Guarapuava com intuito de mapear quantos se inscreveram e quantos foram convocados até mês de março de 2016.

Os dados coletados retirados do site do Núcleo Regional de Educação de GuarapuavaPR foram postos e tabelas para localizar o $n^{\circ}$ de inscritos para o Processo Seletivo e $n^{\circ}$ de convocados para exercer a função.

\section{CONCLUSÃO}

No Brasil ainda é recente a lei que regulamenta a disciplina de Ensino Religioso, pois a emenda do art. 33 da Lei das Diretrizes e Bases da educação ${ }^{10}$, Lei no 9.394 é de 20 de Dezembro de 1996, ou seja, ainda estamos em fase de preparação para termos professores especializados em Ensino Religioso.

Nesse trabalho reconhecemos a importância de professores especializados em Ensino Religioso, porém ainda nem todos os profissionais que dão aula na disciplina são especializados, nessa pesquisa isso se tornou evidente levando em conta a formação dos inscritos para Ensino Religioso em Educação de Campo no município de Guarapuava-PR.

Concluímos ainda que é importante o a existência de políticas públicas voltadas para cursos de especialização de professores, pois é de extrema importância a existência de profissionais especializados na área, pois o perfil do professor de Ensino Religioso envolve a capacidade de saber trabalhar com a diversidade existente na escola, esse professor deve saber conduzir os alunos a refletirem sobre a multiculturalidade e principalmente, saber respeitar as diferentes crenças, ou seja, saber lidar com uma visão conjuntural e utilizar isso no processo de construção do conhecimento.

\section{REFERÊNCIAS}

MARKUS, Cledes. Culturas e religiões: implicações para o ensino. Conselho de missões entre índios - COMIN. São Leopoldo/RS, novembro de 2002

QUEIROZ, Carlos Alberto. Novos rumos do ensino religioso para educação basica. Revista de Ciberteologia. Edição no 41 - Ano IX - Janeiro/Fevereiro/Março 2013 - ISSN: $1809-2888$

10 A “LDB - Lei de Diretrizes e Bases da Educação, no 9.394/96 - ela é uma legislação com a função de organizar a estrutura da educação brasileira, la influencia diretamente na formação escolar e acadêmica". Disponível em <http://soparaprofessoras.blogspot.com.br/2011/05/importancia-dos-pcns-e-da-ldb.html>. Último acesso em: 15/08/2016 
SILVA, Rosilene Ribeiro. Ensino religioso no brasil: em busca de uma identidade. Teresina/PI, 2015

\section{SÓ PARA PROFESSORAS. A IMPORTÂNCIA DOS PCNS E DA LDB.}

Disponível em < http://soparaprofessoras.blogspot.com.br/2011/05/importancia-dos-pens-eda-ldb.html>. Último acesso em: 15/08/2016

NÚCLEO REGIONAL DE EDUCAÇÃO. Disponível em <http://www.educacao.pr.gov.br/arquivos/File/pss/pss_2015_2016/classificacao_final/edital_ 80_classfinal_professor_guarapuava.pdf>. Último acesso em: 15/08/2016

CENTRO DE REFERENCIAS EM EDUCAÇÃO INTEGRAL. EDUCAÇÃO DO CAMPO. Disponível em <http://educacaointegral.org.br/glossario/educacao-no-campo>. Último acesso em: 15/08/2016 